\title{
PET/CT imaging for metastatic choroidal melanoma
}

\section{Imagen de PET/CT de melanoma coroideo metastásico}

\author{
V. Wiwanitkit
}

\section{Dear Director:}

The report on "Whole body PET/CT imaging metastatic choroidal melanoma" is very interesting. Rodríguez-Marco et al concluded that "PET/CT is a sensitive tool for the detection and localization of hepatic and extrahepatic metastatic choroidal melanoma"1. In fact, PET/CT is confirmed for its usefulness in following up choroidal melanoma. Finger et al. noted that "PET/CT imaging may improve upon the conventional methods of screening for detection of metastatic disease in patients initially diagnosed with choroidal melanoma" 2 . Kurli et al also proposed that "same conclusion" as Rodríguez-Marco et al that PET/CT is "is a sensitive tool for the detection and localization of hepatic and extra-hepatic (particularly osseous) metastatic choroidal melanoma"3. However, the limitation of using PET/CT in melanoma is still observed. As noted by Keu and Iagaru, "early stage evaluation of melanoma" is still the challenge that needs further improvement ${ }^{4}$. Finally, the use of whole body PET/CT is limited to detect small metastases ${ }^{5}$. It is suggested to use focused regional PET/CT in those cases suspected for early small metastases ${ }^{5}$.

\section{REFERENCES}

1. Rodríguez-MArco N, Caicedo-Zamudio C, SolanasÁlava S, Gill-Arnaiz I, Córdoba-Iturriagagoitia A, ANDONEGUI-NAVARRo J. Whole body PET/CT imaging for detection of metastatic choroidal melanoma. An Sist Sanit Navar 2014; 37: 293-298.

2. Finger PT, Kurli M, Reddy S, Tena LB, Pavlick AC. Whole body PET/CT for initial staging of choroidal melanoma. Br J Ophthalmol 2005; 89: 1270-1274.

3. Kurli M, Reddy S, Tena LB, Pavlick AC, Finger PT. Whole body positron emission tomography/ computed tomography staging of metastatic choroidal melanoma. Am J Ophthalmol 2005; 140: 193-199.

4. Keu KV, Iagaru AH. The clinical use of PET/CT in the evaluation of melanoma. Methods Mol Biol 2014; 1102: 553-580.

5. Mojtahedi A, Solomon SB, Ulaner GA. Focused regional FDG PET/CT detects more osseous metastases than does whole-body PET/CT. Clin Nucl Med 2013; 38: 217-218.
Tropical Medicine Departament. Hainan Medical University. Haikon. China

Recepción: 8 de septiembre de 2014

Aceptación definitiva: 9 de octubre de 2014

\section{Corresponding author:}

Viroj Wiwanitkit

Tropical Medicine Departament

Hainan Medical University. Haikon. China

E-mail: virojwiwan@hotmail.com 